Pacific Journal of Mathematic 


\title{
A GENERALIZATION OF THE WILDER ARCS
}

\author{
P. H. Doyle and J. G. Hocking
}

Fox and Harrold first used the words "Wilder arc" to describe a wild arc in euclidean 3 -space $E^{3}$ which is the union of two tame arcs meeting only in a common endpoint and which is locally peripherally unknotted (L.P.U.) at this point of intersection. Thus there are imposed (a) conditions upon the embeddings of subarcs of the wild arc and (b) conditions upon the manner in which the subarcs meet. The following definition gives only conditions of type (a): An arc $A \subset E^{3}$ is almost tame if each point of $A$ lies on a tame subarc of $A$. Clearly, every Wilder arc is almost tame.

The chief result characterizes the set $W$ of points on an almost tame arc at which the arc can fail to be locally tame. In particular, $W$ is shown to be homeomorphic to a closed countable set $W^{\prime}$ on the unit interval with the property that a point $x \in W^{\prime}$ either is the first or last point of $W^{\prime}$ or $x$ has either an immediate predecessor or an immediate successor. Two further results discuss special cases.

Lemma 0. If the arc $A \subset E^{3}$ is almost tame, then $A$ is locally tame at each of its endpoints and hence is L.P.U. at these points.

This lemma follows immediately from the definition of an almost tame arc.

Lemma 1. Let $C$ be an uncountable set in the closed unit interval $I=[0,1]$ in $E^{1}$. Then there is a point in $C$ which is a limit point of $C$ both from below and from above.

This follows from Theorem 6, Chapter 1 of [4].

Lemma 2. Let the arc $A \subset E^{3}$ be almost tame and let $W$ denote the set of points of $A$ at which $A$ is not locally tame. Then $W$ is a closed countable subset of $A$. Furthermore, if $h: I \rightarrow A$ is a homeomorphism, then under the order relation induced on $A$ by $h$, one has the property that, for each $x \in W$, (i) $x$ is the first point of $W$ or $x$ is the last point of $W$ or (ii) $x$ has either a unique predecessor or a unique successor.

Proof. The set of points at which $A$ is locally tame is open so $W$ is obviously closed.

Let $x$ be a point of $W$. By Lemma 0 , we have $0<h^{-1}(x)<1$. By assumption of almost tameness, $x$ lies on a tame subarc of $A$. 
Hence there is a maximal connected subset $U$ of $A$ that contains $x$ but no other point of $W$ and $\bar{U}$ is a nondegenerate arc. If neither endpoint of $\bar{U}$ is in $W$, then obviously $\bar{U}=A$ and $x$ is the only point in $W$. Let $y$ be the left-hand endpoint of $\bar{U}$, i.e. $h^{-1}(y) \leqq h^{-1}(x)$. If $h^{-1}(y)<h^{-1}(x)$ and if $y \notin W$, then there is no point of $W$ between $h(0)$ and $x$ so $x$ is the first point of $W$. If $h^{-1}(y)<h^{-1}(x)$ and $y \in W$, then clearly $y$ is the immediate predecessor of $x$ in $W$. If $y=x$, consider the right-hand endpoint $z$ of $\bar{U}$. Since $\bar{U}$ is nondegenerate $h^{-1}(x)<h^{-1}(z)$. If $z \notin W$, then there is no point of $W$ between $x$ and $h(1)$; whence $x$ is the last point of $W$. If $\mathrm{z} \in W$, then $\mathrm{z}$ is the immediate successor of $x$ in $W$.

The set $W$ can not have a limit point both from above and from below under the circumstances just established. Hence by Lemma 1, $W$ is countable.

THeOREM 1. Let $W \subset I \subset E^{3}$ be a closed countable set with the property that a point $x \in W$ either is the first or last point of $W$ or $x$ has either an immediate predecessor or an immediate successor. Then there is an almost tame arc $A \subset E^{3}$ such that $W$ is precisely the set of points at which $A$ is not locally tame.

Proof. Let $B=\left\{a_{i}\right\} \subset W$ be the set of isolated points of $W$. In a small open sphere $U_{i}$ containing $a_{i}$ and no other points of $W$, we introduce a Wilder arc $J_{i}$ [1] as follows: Let $a_{i}$ be the point at which $J_{i}$ is not locally tame and replace the interval $\bar{U}_{i} \cap I$ by $J_{i}$ so that $J_{i}$ has the same endpoints as does $\bar{U}_{i} \cap I$ and so that $J_{i}$ lies in a symmetric cylinder of radius less than $1 / i$ having $\bar{U}_{i} \cap I$ as axis of symmetry while $\left(I-U_{i}\right) \cup J_{i}$ is an arc. If this is done for each $U_{i}$ the result is an arc $A$. Clearly the set $B$ is contained in the set of points at which $A$ is not locally tame. Furthermore each limit point of $W$ is a limit point of the isolated points of $W$ hence $A$ fails to be locally tame at each point of $W$ and only at these points. Clearly every point of $W$ lies on a closed subarc of $A$ which is either homeomorphic to $J_{i}$ or is an interval. Hence $A$ is almost tame.

Theorem 2. Let $A \subset E^{3}$ be an almost tame arc such that each subarc of $A$ is also almost tame. Then $A$ is a union of a finite number of tame arcs.

Proof. Again let $W$ be the set of points of $A$ at which $A$ is not locally tame and suppose that $W$ has a limit point $x$. By Lemma $2, x$ is a limit point of points of $W$ from only one side of $x$. Select a small subarc $J$ in $A$ with $x$ as an endpoint and so that $x$ is a limit point of $J \cap W$. The subarc $J$ is then not almost tame. Hence $W$ 
can contain no limit points and so is finite. It follows immediately that $A$ is a union of finitely many tame arcs, as asserted.

It should be noted that the construction of the $\operatorname{arc} A$ in Theorem 1 gives rise to an arc which is L.P.U. at each of its points. We may define a generalized Wilder arc to be an almost tame arc which is L.P.U. at each of its points. Clearly Theorems 1 and 2 then apply to such arcs. Indeed, we remark that a generalized Wilder arc is necessarily cellular. The converse is not true, of course. The most one can say in this direction is as follows:

Theorem 3. Suppose the almost tame arc $A \subset E^{3}$ is cellular. Then every subarc $J$ of $A$ which is locally tame at its interior points is also locally tame at one of its endpoints.

Proof. From [3] it follows that each subarc of $A$ is cellular. Given a cellular subarc $J$ as in the theorem, 12] then asserts that $J$ is locally tame at one endpoint.

\section{REFERENCES}

1. R. H. Fox and O. G. Harrold, The Wilder Arcs, Topology of 3-Manifolds and Related Topics, Prentice-Hall, Englewood Cliffs, N. J., 1962.

2. J. M. Martin, The sum of two crumpled cubes, Mich. Math. J. 13 (1966), 147-151.

3. D. R. McMillan, A criterion for cellularity in a manifold, Ann. of Math. 79 (1964), 327-337.

4. R. L. Moore, Foundations of Point Set Theory, Amer. Math. Soc. Colloquium Publications, Vol. XIII, (revised edition), 1962.

Received April 6, 1966.

Michigan State University 



\section{PACIFIC JOURNAL OF MATHEMATICS}

\section{EDITORS}

\section{H. SAMELSON}

Stanford University

Stanford, California

J. P. JANS

University of Washington

Seattle, Washington 98105
J. DUGUNDJI

University of Southern California Los Angeles, California 90007

RICHARD ARENS

University of California

Los Angeles, California 90024

\section{ASSOCIATE EDITORS}
E. F. BECKENBACH
B. H. NEumanN
F. WOLF
K. YosidA

\section{SUPPORTING INSTITUTIONS}

\author{
UNIVERSITY OF BRITISH COLUMBIA \\ CALIFORNIA INSTITUTE OF TECHNOLOGY \\ UNIVERSITY OF CALIFORNIA \\ MONTANA STATE UNIVERSITY \\ UNIVERSITY OF NEVADA \\ NEW MEXICO STATE UNIVERSITY \\ OREGON STATE UNIVERSITY \\ UNIVERSITY OF OREGON \\ OSAKA UNIVERSITY \\ UNIVERSITY OF SOUTHERN CALIFORNIA
}

\author{
STANFORD UNIVERSITY \\ UNIVERSITY OF TOKYO \\ UNIVERSITY OF UTAH \\ WASHINGTON STATE UNIVERSITY \\ UNIVERSITY OF WASHINGTON \\ AMERICAN MATHEMATICAL SOCIETY \\ CHEVRON RESEARCH CORPORATION \\ TRW SYSTEMS \\ NAVAL ORDNANCE TEST STATION
}

Mathematical papers intended for publication in the Pacific Journal of Mathematics should be typewritten (double spaced). The first paragraph or two must be capable of being used separately as a synopsis of the entire paper. It should not contain references to the bibliography. Manuscripts may be sent to any one of the four editors. All other communications to the editors should be addressed to the managing editor, Richard Arens at the University of California, Los Angeles, California 90024.

50 reprints per author of each article are furnished free of charge; additional copies may be obtained at cost in multiples of 50 .

The Pacific Journal of Mathematics is published monthly. Effective with Volume 16 the price per volume ( 3 numbers) is $\$ 8.00$; single issues, $\$ 3.00$. Special price for current issues to individual faculty members of supporting institutions and to individual members of the American Mathematical Society: $\$ 4.00$ per volume; single issues $\$ 1.50$. Back numbers are available.

Subscriptions, orders for back numbers, and changes of address should be sent to Pacific Journal of Mathematics, 103 Highland Boulevard, Berkeley 8, California.

Printed at Kokusai Bunken Insatsusha (International Academic Printing Co., Ltd.), 7-17, Fujimi 2-chome, Chiyoda-ku, Tokyo, Japan.

PUBLISHED BY PACIFIC JOURNAL OF MATHEMATICS, A NON-PROFIT CORPORATION

The Supporting Institutions listed above contribute to the cost of publication of this Journal, but they are not owners or publishers and have no responsibility for its content or policies. 


\section{Pacific Journal of Mathematics

Vol. 22, No. $3 \quad$ March, 1967

Wai-Mee Ching and James Sai-Wing Wong, Multipliers and $H^{*}$

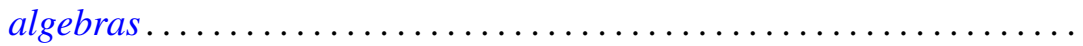

P. H. Doyle, III and John Gilbert Hocking, A generalization of the Wilder

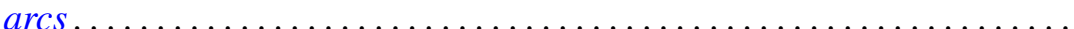

Irving Leonard Glicksberg, A Phragmén-Lindelöf theorem for function

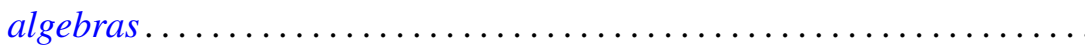

E. M. Horadam, A sum of a certain divisor function for arithmetical semi-groups ..................................... 407

V. Istrăţescu, On some hyponormal operators ................... 413

Harold H. Johnson, The non-invariance of hyperbolicity in partial

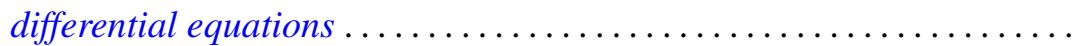

Daniel Paul Maki, On constructing distribution functions: A bounded denumerable spectrum with $n$ limit points................... 431

Ronald John Nunke, On the structure of Tor. II .................... 453

T. V. Panchapagesan, Unitary operators in Banach spaces ............. 465

Gerald H. Ryder, Boundary value problems for a class of nonlinear differential equations ................................. 477

Stephen Simons, The iterated limit condition and sequential convergence .................................... 505

Larry Eugene Snyder, Stolz angle convergence in metric spaces ......... 515 Sherman K. Stein, Factoring by subsets ................... 523

Ponnaluri Suryanarayana, The higher order differentiability of solutions of abstract evolution equations . . .

Leroy J. Warren and Henry Gilbert Bray, On the square-freeness of Fermat and Mersenne numbers ............................... 563

Tudor Zamfirescu, On l-simplicial convexity in vector spaces........... 565 Eduardo H. Zarantonello, The closure of the numerical range contains the spectrum 